\title{
EXEQUIAS POR LA REINA JUANA I EN \\ LONDRES: RELIGIÓN, POLÍTICA Y ARTE*
}

\author{
Miguel Á. Zalama / Jesús F. Pascual Molina
}

Universidad de Valladolid

Recibido: 22-09-2014 / Evaluado: 13-10-2014 / Aprobado: 27-10-2014

Resumen: Alejada de la corte, encerrada en el palacio de Tordesillas, Juana I fue sin embargo la soberana hasta su muerte en 1555. Su hijo y su nieto honraron su memoria con sendos funerales en Bruselas y Londres, que se repitieron a lo largo del reino. No se trataba tan solo de recordar a la difunta, sino sobre todo de trazar la línea sucesoria, dejando claro quién ocupaba el poder. En Londres, estos actos sirvieron también para arremeter contra los protestantes y escenificar la relación que, con los Habsburgo, poseía la reina María Tudor a raíz de su matrimonio con Felipe II.

Palabras clave: Juana I, funerales, Londres, Felipe II, María Tudor.

Abstract: Away from the court and locked in the palace of Tordesillas, Joanna, however, was queen until her death in 1555 . Her son and grandson honored her memory with two funerals that took place in Brussels and London, and which were replicated throughout the kingdom. It was not only about remembering the defunct, but especially to draw the line of succession, making it clear who had the power. In London, these events were also used to attack the Protestants and perform the relationship that Queen Mary Tudor had with the Habsburgs as a result of her marriage with Philip II.

Keywords: Joanna I, funerals, London, Philip II, Mary Tudor.

\footnotetext{
* Este trabajo se ha realizado en el marco del Proyecto de Investigación I+D del Ministerio del Economía y Competitividad HAR2013-41053-P Arte y lujo. Valoración y presencia de los tapices flamencos en España en los siglo XV y XVI y su fortuna posterior. Los autores son miembros del Grupo de Investigación Reconocido de la Universidad de Valladolid Arte, poder y sociedad en la Edad Moderna.
} 
$E^{1}$ comienzo del reinado de María Tudor tuvo un marcado carácter de enfrentamiento, no solo político sino especialmente religioso, si es que ambos pueden separarse totalmente. La reina hubo de plantar cara a varios detractores opuestos a su acceso al trono. Asimismo, la vuelta a la religión católica la enfrentó a los protestantes. ${ }^{1}$ María se sirvió de diversos actos religiosos, como procesiones y sermones, para difundir el credo católico y la vuelta a la obediencia a Roma. Cualquier ocasión era buena para mostrar la adhesión del reino al catolicismo. ${ }^{2}$

Además, tras el matrimonio con el príncipe Felipe, su política se acercaba a los Habsburgo, que veían así ampliarse su ámbito de influencia hasta Inglaterra, algo que no pasa desapercibido no solo en los grandes gestos políticos, sino en pequeños detalles de suma importancia. Así, por ejemplo, la unión entre la reina María y don Felipe se celebró el día de Santiago, 25 de julio, de 1554, dando un trasfondo español al enlace. Aquel momento, además, demostró que el uso de las artes podía estar cargado de un profundo significado político, a veces sutil y en otras de una claridad meridiana. ${ }^{3}$

Las celebraciones cortesanas - procesiones, torneos, banquetes, exequias...eran un marco perfecto para escenificar las relaciones y juegos de poder, poniendo de manifiesto ideologías, alianzas y enemistades. ${ }^{4}$ En este contexto se celebró en Londres el funeral por la reina Juana, fallecida en la localidad de Tordesillas, próxima a Valladolid, el 12 de abril de $1555 .^{5}$

\section{JUANA I, UNA REINA OLVIDADA}

Para quienes frecuentan la historia europea del siglo XVI, la figura de la reina Juana I [Fig. 1] raramente supera lo anecdótico cuando no se limita solo a la leyenda. Su enajenación, es conocida como Juana la Loca, se ha convertido en la principal característica del personaje, con un sesgo literario que ha oscurecido totalmente su verdadero papel histórico: fue reina de Castilla desde 1504, y de Aragón desde 1516, hasta su muerte en 1555. No obstante, fue reina pero apenas gobernó. Otros lo hicieron en su lugar: primero su padre, Fernando el Católico, luego su esposo, Felipe I el Hermoso, quien fue coronado rey junto a doña Juana en 1506, después otra vez su padre hasta fallecer

1. Sobre la restauración del catolicismo en el reinado de María, $c f r$. EAmon Duffy y David Loades (eds.): The Church of Mary Tudor, Aldershot, 2006; y EAmON Duffy: Fires of Faith. Catholic England under Mary Tudor, New Haven - Londres, 2009.

2. Destacaron en este sentido las procesiones, como la del Corpus Christi. Cfr. JoHn Edwards: Mary I England's Catholic Queen, New Haven y Londres, 2011, pp. 252-253.

3. Sobre este tema, $c f r$. Jesús F. PAscual Molina: «'Porque vean y sepan cuánto es el poder y grandeza de nuestro príncipe y señor. Imagen y poder en el viaje de Felipe II a Inglaterra y su matrimonio con María Tudor», Reales Sitios, 197 (2013), pp. 6-25.

4. Para el caso inglés es muy interesante el trabajo de JENNIFER LOACH: «The function of Ceremonial in the Reign of Henry VIII», Past E Present, 142 (1994), pp. 43-68.

5. Miguel Ángel Zalama: Vida cotidiana y arte en el palacio de la reina Juana I en Tordesillas,

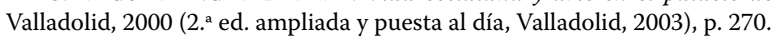


en 1516, y a partir de entonces lo hizo su propio hijo, el futuro emperador Carlos V, sin olvidar los dos interregnos del cardenal Cisneros. No se la relegó por alguna razón oculta, de hecho se le pidió con insistencia que tomase las riendas del gobierno en Castilla tras la inopinada muerte de su esposo el 25 de septiembre de 1506, petición que también hicieron los comuneros en 1520, mas siempre fue en vano; Juana I se negó a reinar, y lo hizo porque sus

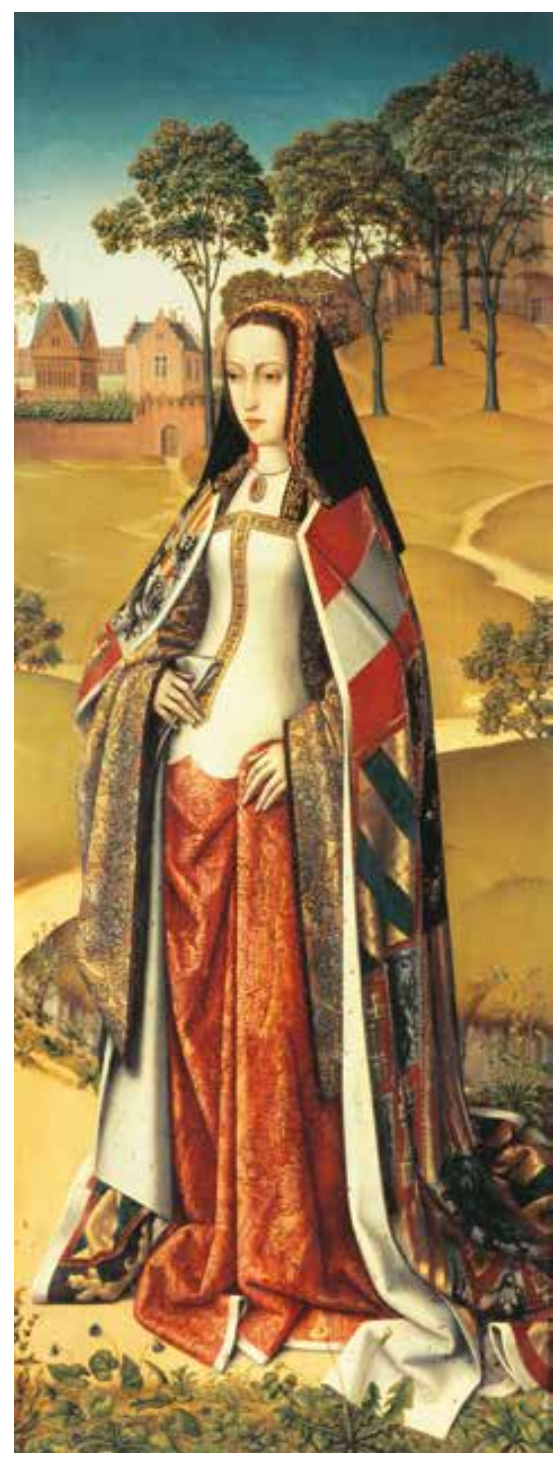

Fig. 1. Maestro de la vida de José o de Afflighem; ¿Jacob van Laethem?, Juana I, ca. 1505. Óleo sobre tabla, $125 \times 48 \mathrm{~cm}$. Bruselas, Musées Royaux des Beaux-Arts de Belgique 
facultades mentales estaban alteradas, lo que se aprecia en escritos de sus padres, los Reyes Católicos, en las cartas de contemporáneos, como Pedro Mártir de Anglería, del embajador de la República de Venecia en los Países Bajos, Vincenzo Querini, o en las declaraciones de sirvientes de la soberana. ${ }^{6}$ Que la soberana hiciese dejación de sus funciones como gobernante suponía un considerable problema. Otros tendrían que hacerlo por ella, pero cabía la posibilidad de que la reina recuperase la salud mental y aquel que ostentase el poder podía perderlo inmediatamente, pues Juana I nunca dejó de ser la reina. De esta manera lo entendieron las Cortes de Castilla que a comienzos del 1518 juraron al príncipe Carlos como monarca, al que dejaron claro que doña Juana era «reina y señora de estos reinos», y meses después las Cortes de Aragón se mostraron renuentes a su proclamación porque «iba contra las leyes, por ser la reina propietaria viva»; ${ }^{7}$ así lo entendió el gobernador de Castilla en ausencia de Carlos V, Adriano de Utrech, futuro papa Adriano VI, quien durante el conflicto de las Comunidades, y ante la posibilidad de que la soberana sancionase los escritos que le presentaban los líderes comuneros para que apoyase su causa, escribió a su señor diciendo: «Si firma su alteza que sin duda ninguna todo el reyno se perderá y saldrá de la real obediencia de V. M., assí que mire por merced en qué puncto y quán dudoso está vuestro real estado de España». ${ }^{8}$ Sabedor de este problema, ya Fernando el Católico se cuidó de que su hija no cayese en manos de facciones de la nobleza que pudiesen utilizarla como bandera de sus propios intereses. Así, en 1509 decidió encerrarla -el término no es exagerado pues de hecho la reina tuvo totalmente limitados sus movimientos- en el palacio de Tordesillas [Fig. 2], villa bien comunicada situada a $30 \mathrm{~km}$ de Valladolid; lo suficientemente lejos para, con los medios de transporte de la época, no poderse presentar una turba desde Valladolid exigiendo su liberación, y a la vez no tan apartada como para no poder mover gente de armas en poco tiempo, por si fuese necesario responder a algún ataque al palacio.

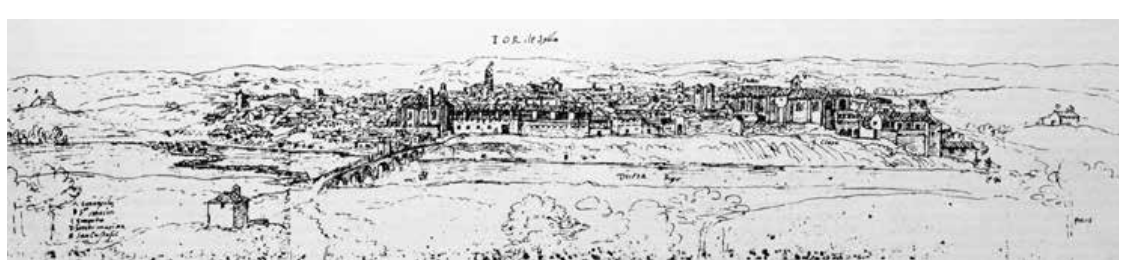

Fig. 2. Anton van den Wyngaerde, Vista de Tordesillas, 1565-1570. Pluma y tinta sepia sobre papel, 15,2 × 75,7 cm. Londres, Victoria \& Albert Museum

6. Cfr. Zalama, Vida cotidiana; IDEM: Juana I. Arte, poder y cultura en torno a una reina que no gobernó, Madrid, 2010.

7. Prudencio de Sandoval: Historia de la vida y hechos del emperador Carlos $V$ (ed. de C. Seco Serrano), I, Madrid, 1955 [1604], pp. 128 y 139-140.

8. Gustav Adolf Bergenroth: Supplement to volume I. and volume II. of Letters, Despatches, and State papers, relating to negotiations between England and Spain, preserved in the Archives at Simancas and elsewhere, Londres, 1868 (reed. Nendeln, Liechtenstein, 1969), pp. 304-305. 
Juana I permaneció alejada de cualquier mirada en Tordesillas hasta su muerte en 1555; solo abandonó su residencia en 1533-1534 como consecuencia de la peste que asoló durante meses la villa y se cobró víctimas entre los servidores de palacio. No quedó otro remedio que sacar a la reina del lugar, pero teniendo mucho cuidado de que no fuese a ninguna localidad importante, donde pudiese ser reconocida y aclamada. El esfuerzo que se hizo para conseguir que su reclusión fuese como la de un convento de estricta observancia, de donde no salieran ni entraran noticias, algo en lo que incidía el carcelero Bernardo de Sandoval y Rojas, II marqués de Denia, ${ }^{9}$ hombre a quien Carlos V confió la custodia de la reina, dio sus frutos; cuando la reina falleció prácticamente se había perdido su memoria.

\section{Honras fúnebres por Juana I en España y los Países Bajos}

Tras casi medio siglo de reinado, sin bien al margen del gobierno, Juana I falleció en su palacio de Tordesillas el 12 de abril de 1555. Su muerte no sorprendió a nadie; su avanzada edad para la época, 76 años, y el progresivo deterioro físico de los últimos meses, anunciaban el fatal desenlace. A pesar de ello ni un solo miembro de la familia real estuvo presente. Carlos V estaba en Bruselas; Fernando de Habsburgo, el segundo hijo varón de la reina, permanecía en Viena en tanto que rey de Bohemia y Hungría; Leonor de Austria y María de Hungría estaban junto a su hermano Carlos V, y Catalina, reina de Portugal, y que vivió en Tordesillas hasta 1525, residía en Lisboa. Tampoco estuvo su nieto, el príncipe Felipe, entonces rey de Inglaterra por su matrimonio con María Tudor, ni la hermana de este, María, esposa de Maximiliano de Austria. La hija menor de Carlos V, la princesa Juana de Portugal, a la sazón regente, estaba cerca, en Valladolid, pero no acudió cuando falleció su abuela, como tampoco lo hizo su biznieto, el príncipe Carlos, que asimismo residía en la misma ciudad. Certificó su muerte su último carcelero, el III marqués de Denia, junto con algunos personajes como el jesuita Francisco de Borja. Tres días después del óbito se procedió a inhumar a la reina en la capilla mayor de la iglesia del monasterio de Santa Clara. Al entierro tampoco asistieron ni su nieta ni su biznieto; la comitiva que partió del palacio hasta el cercano monasterio iba encabezada por el condestable de Castilla, Pedro Fernández de Velasco, y los prelados Antonio de Fonseca, presidente del Consejo Real, y Antonio del Águila, obispo de Zamora. ${ }^{10}$

Nada indica que la ceremonia tuviese el boato propio de un entierro regio. Después de casi medio siglo de ocultamiento, su familia debió entender que no era procedente llamar la atención sobre la existencia de la reina. Se había tenido mucho tiempo para preparar las honras fúnebres y, sin embargo, se limitaron

9. Antonio Rodríguez Villa: La reina doña Juana la Loca, Madrid, 1892, pp. 279-281.

10. Zalama, Juana I. Arte, poder y cultura, pp. 345-346. 


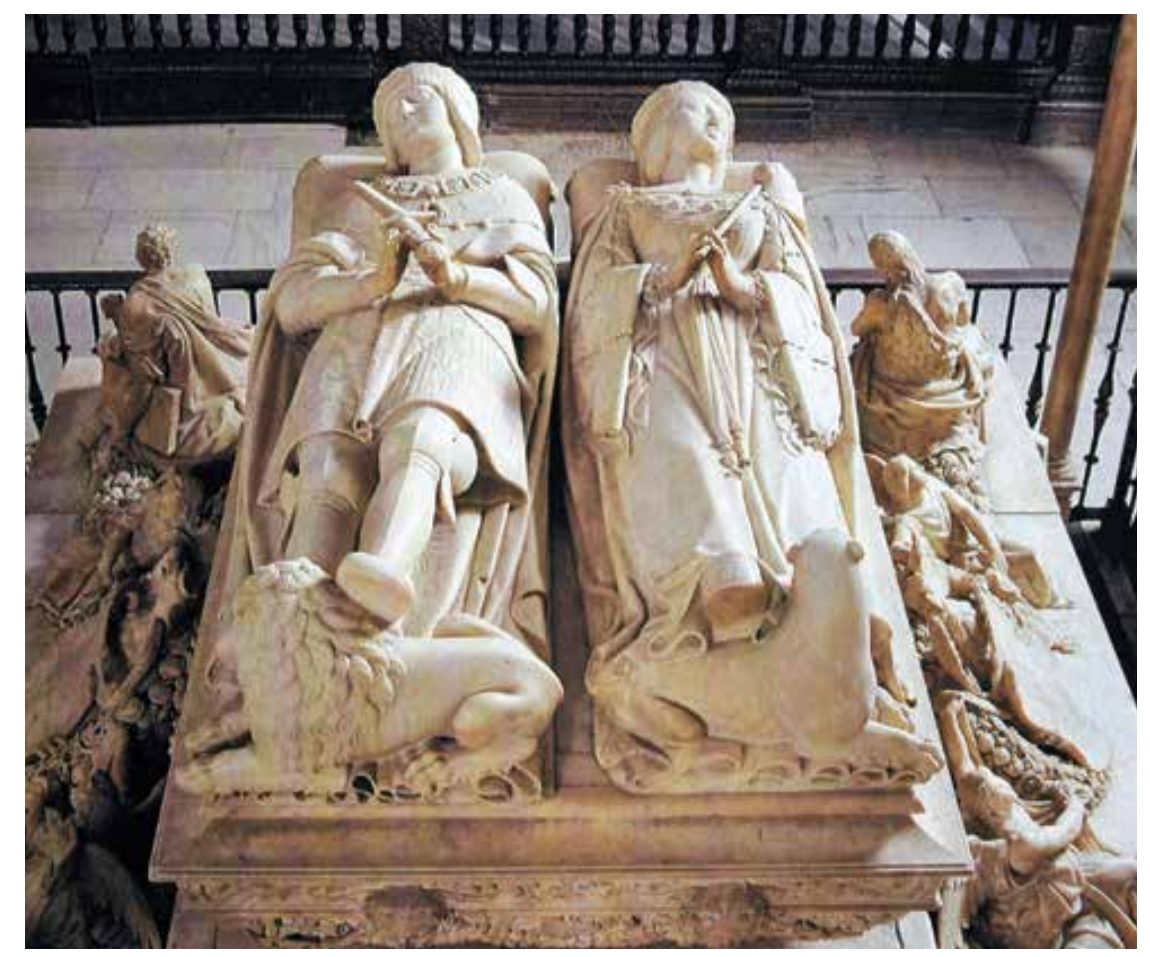

Fig. 3. Bartolomé Ordoñez, Sepulcro de Felipe I y Juana I, ca. 1519. Mármol. Granada, Capilla Real

a introducir el cuerpo en la sepultura que se había abierto en la capilla mayor de la iglesia de las clarisas, donde una cama cubierta por un paño de terciopelo negro, rodeada por una reja de madera decorada con doce escudos, señalaba el espacio donde se encontraba el cuerpo de la soberana. Solo en 1564, viendo que el traslado de sus restos a la Capilla Real de Granada [Fig. 3], donde ya estaban los de su esposo, se iba a demorar -de hecho aún habría que esperar una década-, Felipe II ordenó aderezar los altares laterales. ${ }^{11}$

Enterrada la reina, el siempre latente peligro de que se reivindicase su existencia desapareció. Carlos $\mathrm{V}$ ya no compartía de jure, pues de facto jamás la compartió, la corona con su madre y podía centrarse en la abdicación, como hizo solo unos meses después. Ya no importaba hablar de la reina Juana, pues estaba muerta, y como en el caso de otros monarcas tuvieron lugar honras fúnebres en diferentes partes del reino. En Valladolid, donde residía la corte, se celebraron funerales en la iglesia del monasterio de San Benito, presididos por 


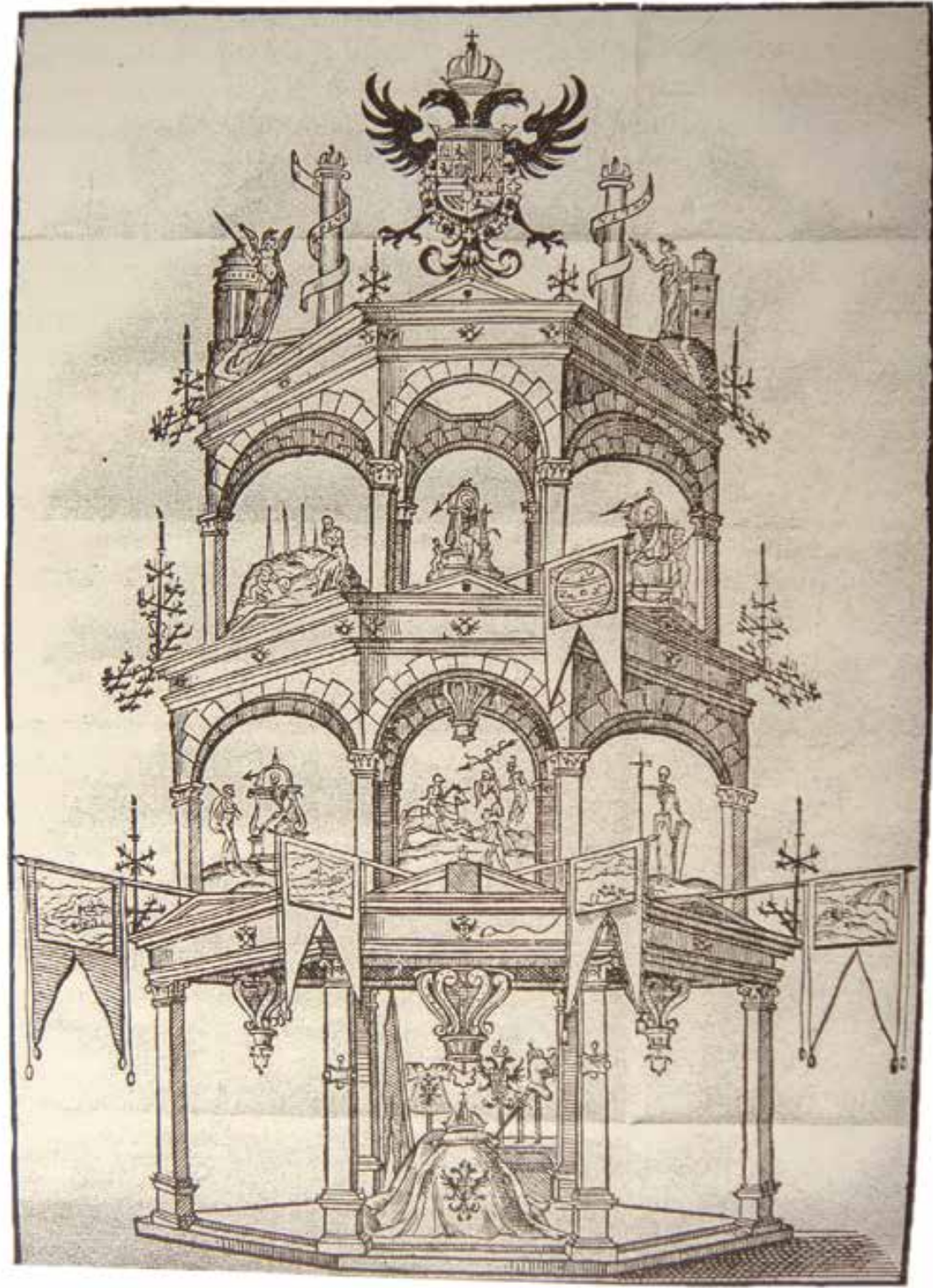

Fig. 4. Túmulo de las honras fúnebres de Carlos V celebradas en San Benito de Valladolid, grabado en J. Calvete de Estrella, El túmulo imperial adornado de historias y letreros y epitaphios en prosa y verso latino, Valladolid, 1559 
el príncipe Carlos, pues su tía, la princesa Juana, no participó. El arquitecto Francisco de Salamanca recibió la considerable suma de 100 ducados por levantar un túmulo, del que carecemos de noticias precisas, pero que no debió ser muy diferente del que el mismo arquitecto realizó tres años después para los funerales por Carlos V. ${ }^{12}$ Este lo conocemos gracias a la descripción de Juan Calvete de Estrella, ${ }^{13}$ quien incorpora un dibujo [Fig. 4] en el que se muestra un túmulo conformado en tres pisos, de planta hexagonal, rodeado de banderas y escudos.

Además del obligado funeral en Valladolid, en tanto que residencia de la corte, también se hicieron funerales en diferentes lugares: Barcelona, Sevilla, Burgos, Teruel, ${ }^{14}$ y especialmente en Zaragoza «visto y considerado que era reina y señora natural». ${ }^{15} \mathrm{Y}$ no solo se realizaron en España: Carlos V se ocupó de los que tuvieron lugar en Bruselas y Felipe II de los de Londres. El emperador quiso honrar adecuadamente la memoria de su madre, quizá porque no lo había hecho en vida, a la vez que mostrar al mundo que el reino era solo suyo y podía disponer de él, como inmediatamente hizo al abdicar en su hijo. Es evidente que esto estaba previsto en la ceremonia fúnebre, pues se retrasó hasta el 16 de septiembre, cuando ya habían transcurrido cinco meses de la muerte de Juana I, para esperar que llegase el príncipe Felipe, rey de Inglaterra, que se trasladó desde Londres. Era necesaria la presencia del heredero, quien solo un mes después se convirtió en duque de Borgoña y en enero de 1556 en Felipe II, después de la abdicación de su padre. Para poder renunciar al reino en su hijo, Carlos $\mathrm{V}$ previamente debía ser el rey propietario, y hasta la muerte de Juana I legalmente solo lo compartía. Los funerales de Bruselas dejaban bien claro que Carlos I de España era el único rey.

La comitiva fúnebre partió del palacio de Coudenberg hasta la iglesia de San Miguel y Santa Gúdula, que permanecía cubierta de paños de color negro con el escudo de armas de Juana I, alternadas con cruces de tafetán rojo. En el centro había dos ángeles que sostenían el escudo de la reina sobre el que había una corona cuajada de pedrería, y en los cuatro ángulos de la capilla mortuoria otros ángeles portaban los cuatro cuarteles de las armas de doña Juana, bordados en oro y seda. A la derecha del altar mayor se colocó un dosel para Felipe II, pues Carlos V no asistió al funeral, y se levantaron treinta altares pequeños alrededor de la iglesia, todos con colgaduras negras. El recorrido desde el palacio a la iglesia se marcó con columnas forradas con telas negras y grandes antorchas, por el que marcharon, ordenados de menor a mayor importancia, caballeros del Toisón de Oro y de las órdenes militares, obispos, miembros de Consejo Real, embajadores... A continuación, iban los maceros y

12. Ibidem, p. 257

13. Juan CAlvete de Estrella: El túmulo Imperial adornado con Historias, Letreros y Ephitaphios en prosa y verso latino, Valladolid, 1559.

14. María Adelaida Allo Manero: Exequias de la Casa de Austria en España. Italia e Hispanoamérica, tesis doctoral, Universidad de Zaragoza, 1993, pp. 213-217;

15. JuAn José Polo Rubio: «Exequias a la muerte de Juana I la Loca. 1555», Xiloca, 14 (1994), pp. 53-56. 
mayordomos del rey y de las reinas -las hijas de doña Juana, Leonor de Austria y María de Hungría, permanecieron junto a su hermano el emperador y no formaron parte de la comitiva- y un caballo cubierto con una gualdrapa de terciopelo negro bordado en oro, que llegaba hasta el suelo, con las armas de Juana I. Sobre la gualdrapa iba una silla de montar, de mujer, recamada de oro y encima una corona adornada con piedras preciosas. Rodeado de heraldos, tras la montura iba el gran maestre de la Orden del Toisón de Oro y a continuación el príncipe Felipe, quien se mostraba como rey en tanto que lo era de Nápoles y consorte de Inglaterra. Marchaba a pie, vestido de negro con una larga loba con el capuchón sobre la cabeza. La loba la sujetaban el duque de Medinaceli, el conde de Arundel, mayordomo mayor de la reina de Inglaterra, en la parte delantera, y don Antonio de Toledo, caballerizo mayor del rey, y Ruy Gómez de Silva, sumiller de Corps, detrás. A continuación de don Felipe caminaban el nuncio de Su Santidad, los embajadores de Venecia y Florencia, los presidentes de los Consejos..., rodeados de archeros y alabarderos alemanes y españoles. Ya en el interior de la iglesia, el príncipe-rey se puso bajo su dosel y comenzó la vigilia en la que se cantaron nueve salmos y otras tantas lecciones. Terminadas las exequias, la comitiva regresó por el mismo orden al palacio de Coudenberg. $\mathrm{Al}$ día siguiente don Felipe acudió a misa de réquiem por el alma de su abuela; tras la ofrenda comenzó el sermón a cargo del francés fray Antonio Hauet, que alabó las buenas costumbres y virtudes de la reina. Concluida la ceremonia, Felipe II regresó a palacio montado a caballo; las honras fúnebres por Juana I habían terminado. ${ }^{16}$

\section{DOÑA JUANA EN INGLATERRA}

Especial importancia tuvieron los funerales por Juana I en Londres. Sin duda se llevaron a cabo porque el rey consorte era su nieto, pero también porque la reina María Tudor [Fig. 5] era su sobrina, en tanto que hija de la hermana menor de doña Juana, Catalina de Aragón. No obstante, la reina Juana había tenido una relación directa con Inglaterra medio siglo antes de su fallecimiento, pero incluso con anterioridad ya había estado en la isla. El 22 de agosto de 1496 la infanta Juana partió de España para reunirse con su esposo, el archiduque de Austria y duque Borgoña Felipe el Hermoso. El viaje se hizo por mar, desde Laredo (Cantabria), pero una tormenta que les alcanzó el último día del mes, obligó a las naves a resguardarse en las proximidades de Portland. Aunque a la postre no fue más que una escala sin importancia, solo dos días más tarde se reinició el viaje, los principales de la zona se acercaron a mostrar sus respetos a la infanta española. ${ }^{17}$ Una década después, Juana I

16. Rodríguez Villa, La reina, pp. 515-518.

17. Lorenzo de Padilla: Crónica de Felipe I llamado el Hermoso (Ed. de M. Salvá y P. Sainz de Baranda), CODOIN, VIII, Madrid, 1846, p. 38. 


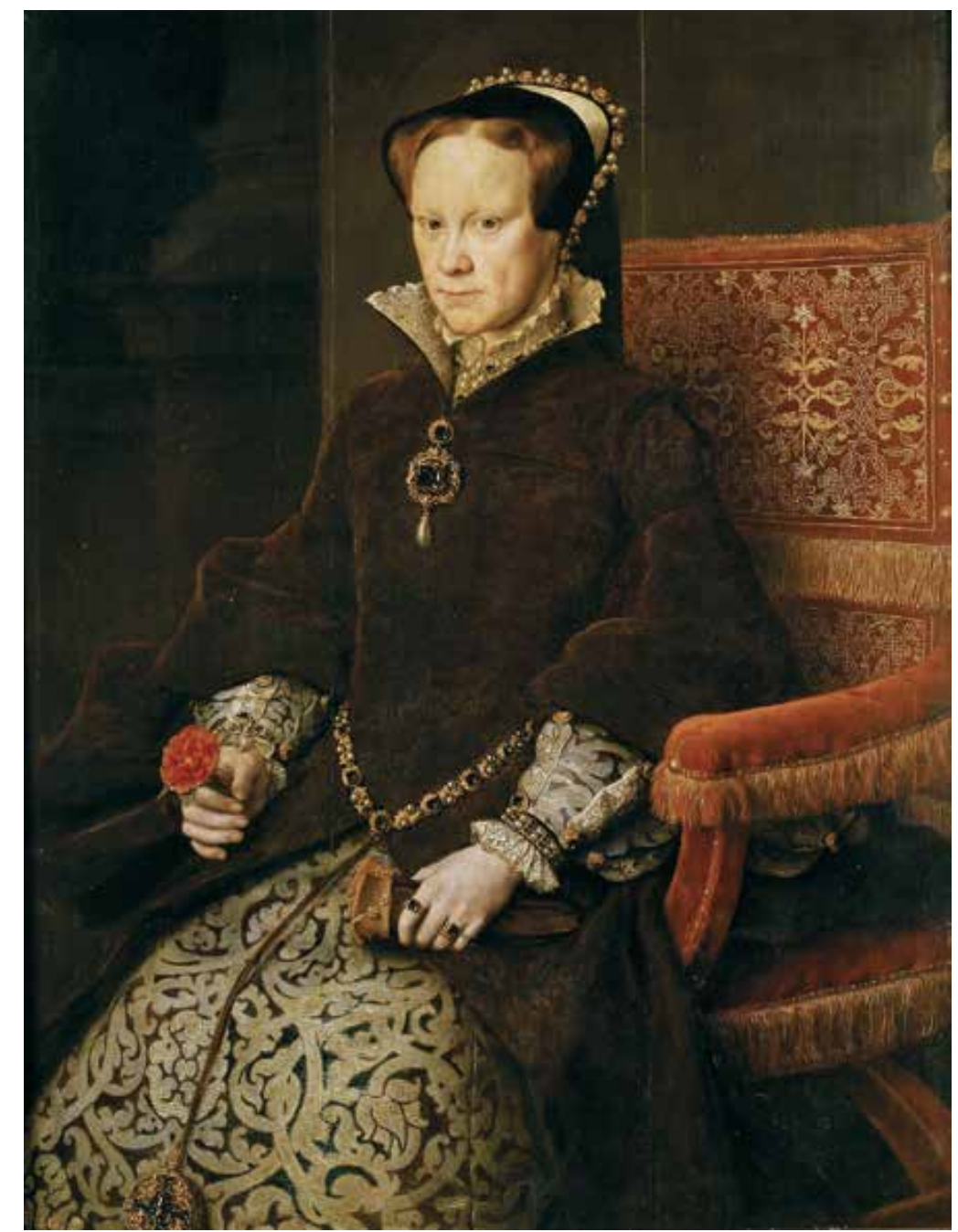

Fig. 5. Antonio Moro, María Tudor, 1554, Óleo sobre tabla, $109 \times 84 \mathrm{~cm}$. Madrid, Museo Nacional del Prado

volvió a Inglaterra, también por los efectos de una tormenta, en este caso temporal, que arrastró y dispersó las naves por las costas de Southampton. La nao en la que viajaban Felipe y Juana arribó a Melcombe, una localidad cercana a Weymouth, frente a la isla de Portland. ${ }^{18}$ La reina regresaba a

18. Gillian Beatrice Fleming: «La visita a Inglaterra de Juana I (enero-abril de 1506)», en Miguel Ángel Zalama (dir.): Juana I en Tordesillas: su mundo, su entorno, Valladolid, 2010, pp. 409-410. 
Castilla junto a su esposo, para ser reconocidos por las Cortes y ponerse al frente del gobierno, hasta ese momento ostentado por Fernando el Católico. Las desavenencias entre Felipe el Hermoso y su suegro por mantener el poder en Castilla, llevaron al borgoñón a hacerse a la mar el 10 de enero de 1506, época del año desaconsejada por los marinos, que sabían de las dificultades que podía conllevar. Tres días después se levantó un temporal que dispersó la flota e hizo naufragar a un tercio de los navíos. ${ }^{19}$

Ante el desastre, no quedó otro remedio que permanecer en Inglaterra mientras se reparaban las embarcaciones que habían conseguido ponerse a resguardo. Enrique VII no perdió el tiempo en llamar a su invitado a la fuerza a Windsor. Felipe el Hermoso y Juana partieron el 21 de enero e hicieron el camino juntos hasta Winchester, donde llegaron el día 28 y se alojaron en casa de Richard Fox, obispo de la ciudad. Sin que se conozcan las razones, doña Juana no siguió adelante con su esposo, quien llegó a la corte el último día de enero. ${ }^{20}$ En el camino le salió a recibir el príncipe de Gales, el futuro Enrique VIII, quien se encargó de agasajar al archiduque mientras se preparaba una gran recepción, de manera que cuando Felipe el Hermoso llegó a Windsor se sorprendió por la riqueza que mostraba el palacio, con estancias decoradas con magníficas tapicerías flamencas. ${ }^{21}$ Allí se le obsequió con una comida amenizada con músicos y en la que se pudo ver «gran cantidad de vajilla de oro y de plata»,22 algo habitual en todas las cortes y que mostraba el poderío de su poseedor. Doña Juana no se acercó a la corte hasta el 10 de febrero, donde residía su hermana, Catalina, en aquellos momentos viuda del príncipe Arturo. ${ }^{23}$ Parece ser que doña Juana apenas permaneció una jornada en Windsor -el cronista inglés dice que estuvo tres días, lo que no se acomoda al hecho de que Catalina abandonase el palacio al día siguiente para trasladarse a Richmond-, y partió para Exeter, y luego a Falmouth, donde se estaba preparando la flota, ${ }^{24}$ aunque hubo que esperar hasta el 23 de abril para reemprender el viaje a España.

Tres meses permaneció doña Juana en Inglaterra, si bien apartada de la corte, ${ }^{25}$ mas no acaba aquí su relación. Enrique VII había enviudado en 1503 y no descartaba volver a contraer matrimonio. Quizá alentado por Catalina de Aragón, el rey inglés comenzó a interesarse por Juana I pocos meses después de que falleciera Felipe el Hermoso. Desde comienzos de 1507 hay correspondencia entre Enrique VII y Fernando el Católico sobre la posibilidad

19. Zalama, Juana I. Arte, poder y cultura, pp. 186-188.

20. FLEMING, «La visita a Inglaterra», p. 414.

21. Thomas P. Campbell: Henry VIII and the Art of Majesty. Tapestries at the tudor Court, New Haven y Londres, 2007, p. 95.

22. «Segundo viaje de Felipe el Hermoso a España en 1506», en JosÉ García MerCadal: Viajes de extranjeros por España y Portugal, I, Madrid, 1952, pp. 566-567.

23. FLEMING, «La visita a Inglaterra», pp. 407-426.

24. Jerónimo Zurita: Historia del rey don Hernando el Cathólico. De las empresas y ligas de Italia, Zaragoza, 1580

25. Las causas de su alejamiento en Zalama: Juana I. Arte, poder y cultura, pp. 188-191. 


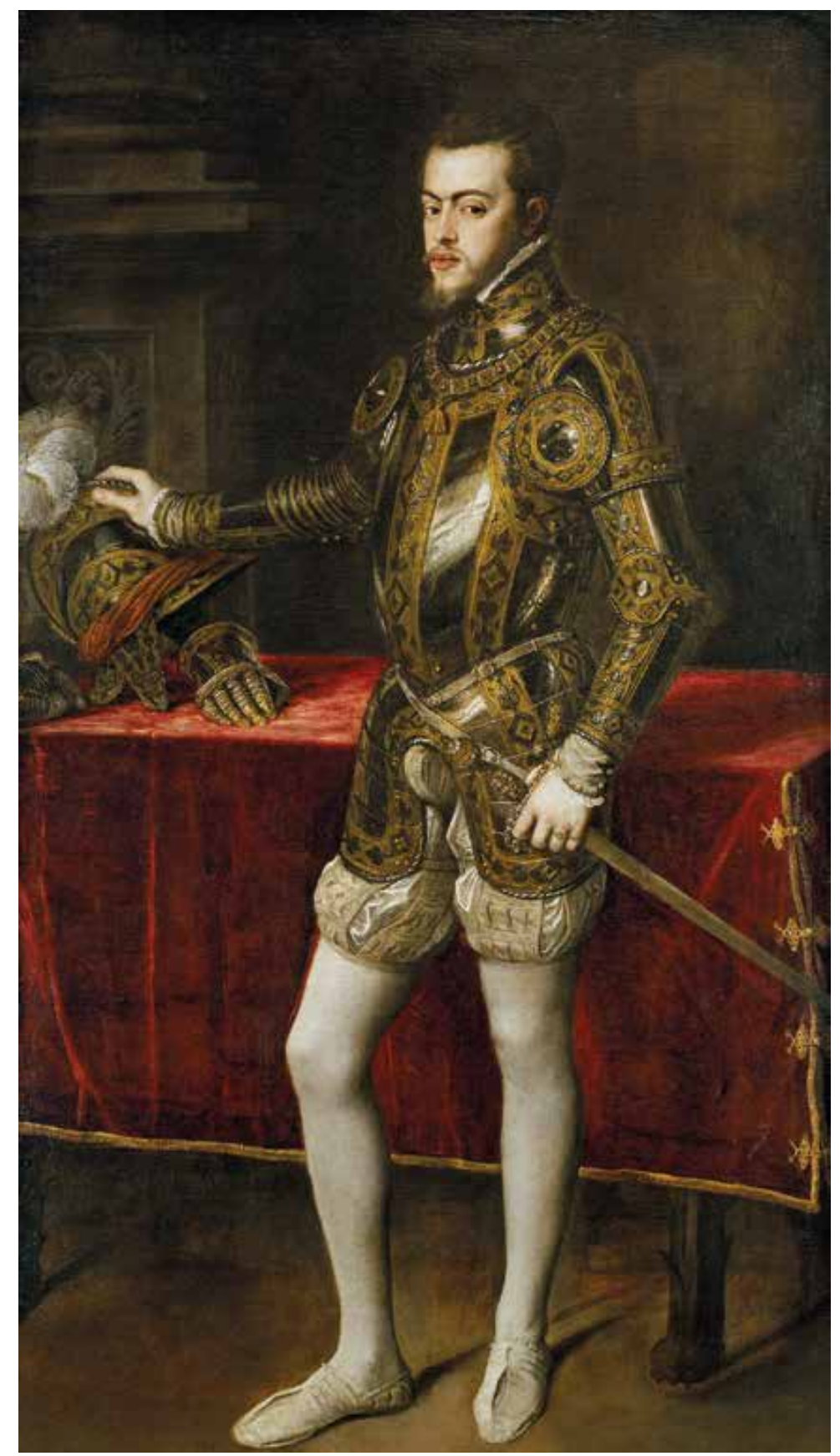

Fig. 6. Tiziano, Felipe II, 1551. Óleo sobre lienzo, $193 \times 111 \mathrm{~cm}$. Madrid, Museo Nacional del Prado 
de llevar a cabo el matrimonio. ${ }^{26}$ No obstante, al rey de Aragón no le interesaba que su hija pudiese ser manejada por otro que no fuese él, pues ya había tenido una amarga experiencia con Felipe el Hermoso. Por ello dio largas al rey de Inglaterra hasta que este, en el verano de 1508, perdió toda esperanza, convencido, como era cierto, de que si no se había llevado a cabo la empresa había sido por la negativa de Fernando el Católico, a quien acusaba de ser el culpable. $^{27}$

\section{FUNERALES EN LONDRES}

La noticia del fallecimiento de doña Juana llegó a Inglaterra, donde el rey Felipe [Fig. 6] quería «dissimular fin dopo il parto della Serenissima Regina la morte della Regina Giovanna di Spagna». ${ }^{28}$ Refiere el embajador veneciano Giovanni Michiel, cómo la muerte de la reina se conocía desde mediados de mayo, si bien «era tenuta occulta», ${ }^{29}$ para no entristecer a la reina María, y que esto pudiera acarrear complicaciones en su gestación, pues parecía encontrarse encinta. Sin embargo, publicada la noticia por la corte imperial, «e stata Sua Maesta accomodarsi all'uso del Serenisimo uso padre, et vestirsi anchor essa con tutta la corte di duolo, senza altra dilatatione». ${ }^{30}$

María Tudor dispuso lo necesario para honrar la memoria de su tía. No solo se trató de un acto de carácter familiar, sino que además sirvió para afianzar los lazos con la casa de Habsburgo y para reforzar la vuelta a la fe católica, como veremos. Se escribieron cartas de pésame a diversos miembros de la familia de la difunta, recibiendo respuesta de Carlos V, y de sus hermanas María de Hungría y Leonor de Austria, quienes agradecían las condolencias. ${ }^{31}$ En España se recibió también noticia de que en Inglaterra se iban a celebrar los funerales. ${ }^{32}$

El día 7 de junio, Lord Treasurer [Fig. 7], encargado de los gastos de la Casa Real, comenzaba los preparativos y la libranza de los lutos, y escribía al obispo de Londres en estos términos:

And your Lordship must command your sextons of the church to be in a readiness of ringing in the time of service. And if ye be not furnished with black apparel for the altar, and for the priest, deacon, and sub-deacon, I must have

26. Bergenroth, Supplement, p. 100.

27. Zalama, Juana I. Arte, poder y cultura, pp. 231-232.

28. Paul Friedmann (ed.): Les dépêches de Giovanni Michiel ambassadeur de Venise en Angleterre, Venecia, 1869, p. 43

29. Idem.

30. Ibidem, p. 44.

31. William B. Turnbull (ed.): Calendar of State Papers, Foreign Series, of the Reign of Mary, 15531558, Londres, 1861, p. 174.

32. Ags (Archivo General de Simancas) Estado, leg. 808, fol. 151. Ruy Gómez de Silva informa al secretario Eraso de que en Londres se celebran las honras por la reina difunta. 
knowledg therof, that it be taken of the Queen's stuff: wherof I pray you let me be advertised..$^{33}$

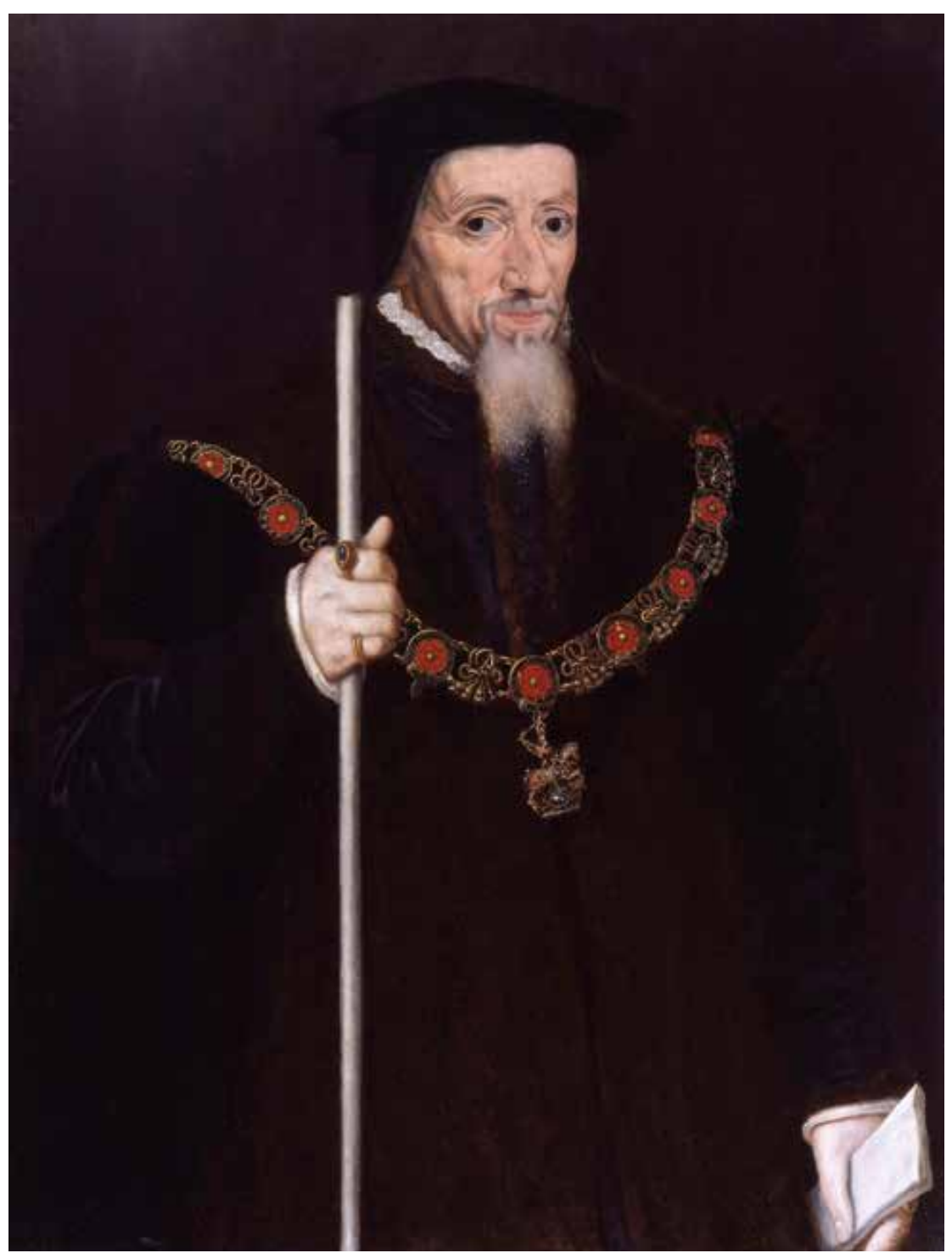

Fig. 7. Anónimo, Retrato de William Paulet, primer marqués de Winchester, ca. 1560. Óleo sobre tabla, 90,5 × 67,6 cm. Londres, National Portrait Gallery

33. John Strype: Ecclesiastical Memorials, III, Londres, 1721, p. 220. 


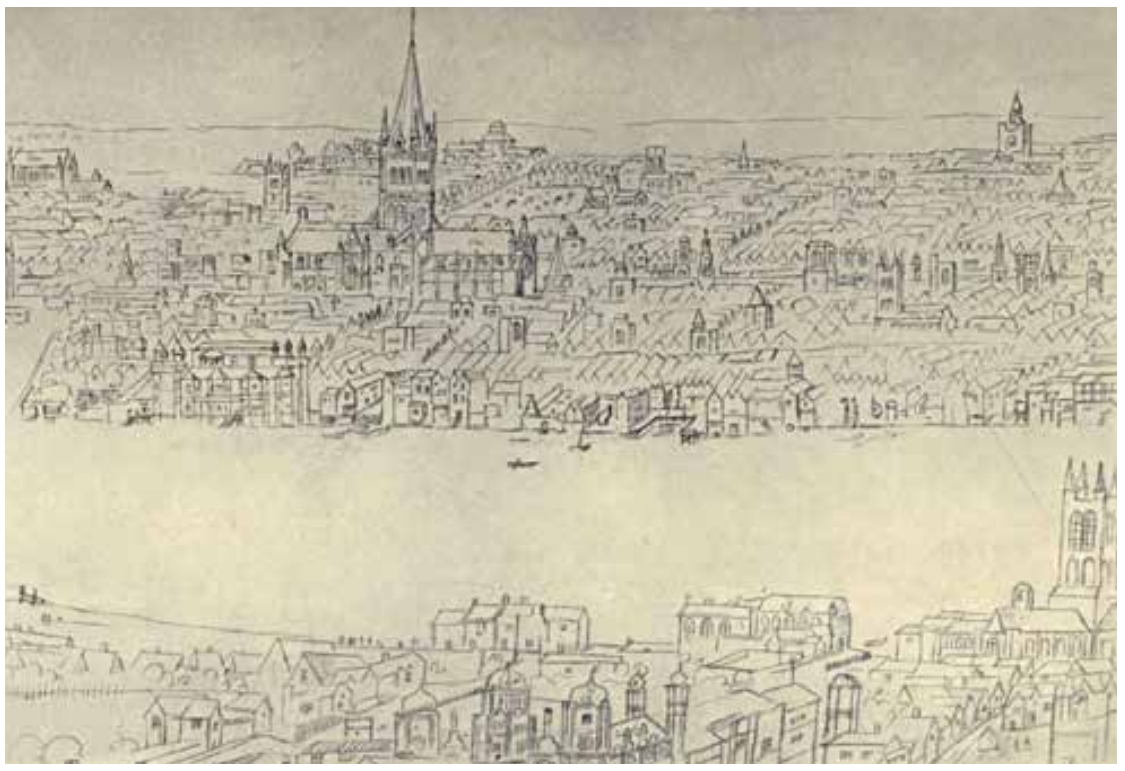

Fig. 8. Según dibujo de Anton van der Wyngaerde, Catedral de San Pablo, ca. 1550, conservado en el Ashmolean Museum de Oxford, publicado en William Benham y Charles Welch, Mediceval London, Londres, 1901

Entre los días 11 y 17 de junio se erigió en la catedral de San Pablo [Fig. 8] un suntuoso túmulo, «the which was the goodlest that ever was sene in England», como apunta el comerciante Henry Machyn en su diario. ${ }^{34}$ En los funerales ingleses, el túmulo no poseía un especial desarrollo arquitectónico, permaneciendo prácticamente invariable en su forma básica a lo largo del Medievo y la Edad Moderna, siendo apenas una estructura de madera destinada a soportar todo el aparato ornamental de carácter heráldico, a base de escudos y banderas de diversos tamaños, así como todo el conjunto de velas, candeleros y demás cera que ardía durante el ceremonial. ${ }^{35}$ De forma

34. John Gough Nichols (ed.): The diary of Henry Machyn, Londres, 1848, p. 90. Henry Machyn, ciudadano de Londres, comerciante dedicado al textil, redactó un interesante diario entre 1550 y 1563 , donde da numerosas noticias de la vida en la capital inglesa, especialmente relacionadas con ceremonias fúnebres y ceremonias religiosas, que él conocía bien por su trabajo de proveedor de telas. Su diario es una fuente indispensable para el conocimiento y estudio de estas prácticas en la Inglaterra del siglo XVI. El manuscrito de esta crónica se conserva, dañado debido a un incendio, en la British Library (Diary of Henry Machyn, British Library, Manuscripts, Cotton Vitellius F.v.). Una edición más reciente, que aporta además el texto modernizado: Richard W. Bailey, Marylin Miller y Colette Moore (eds.): A London Provisioner's Chronicle, 1550-1563, by Henry Machyn: Manuscript, Transcription, and Modernization, Michigan, 2006. Las referencias al funeral de doña Juana en fol. $46 \mathrm{v}$.

35. Sobre los funerales nobiliarios ingleses en la Edad Moderna, $c f r$. JENNIFER WoOdWARD: The Theatre of Death. The ritual management of royal funerals in Renaissance England, 1570-1625, Woodbridge (Suffolk, Reino Unido), 1997. Numerosos datos también en Nichols (ed.), The diary, pp. XX-XxxiI. 
poligonal con número de lados variable, poseía una serie de principals, suerte de pináculos elevados sobre los postes y que sobre los que se disponía la cera que ardía durante el funeral. En el centro solía situarse uno más alto que los demás, el chief principal, conectado a los otros mediante una estructura de arbotantes llamados ratchments, sobre los que también se colocaban velas. El túmulo se pintaba de negro y se cubría con telas del mismo color [Figs. 9 y 10].

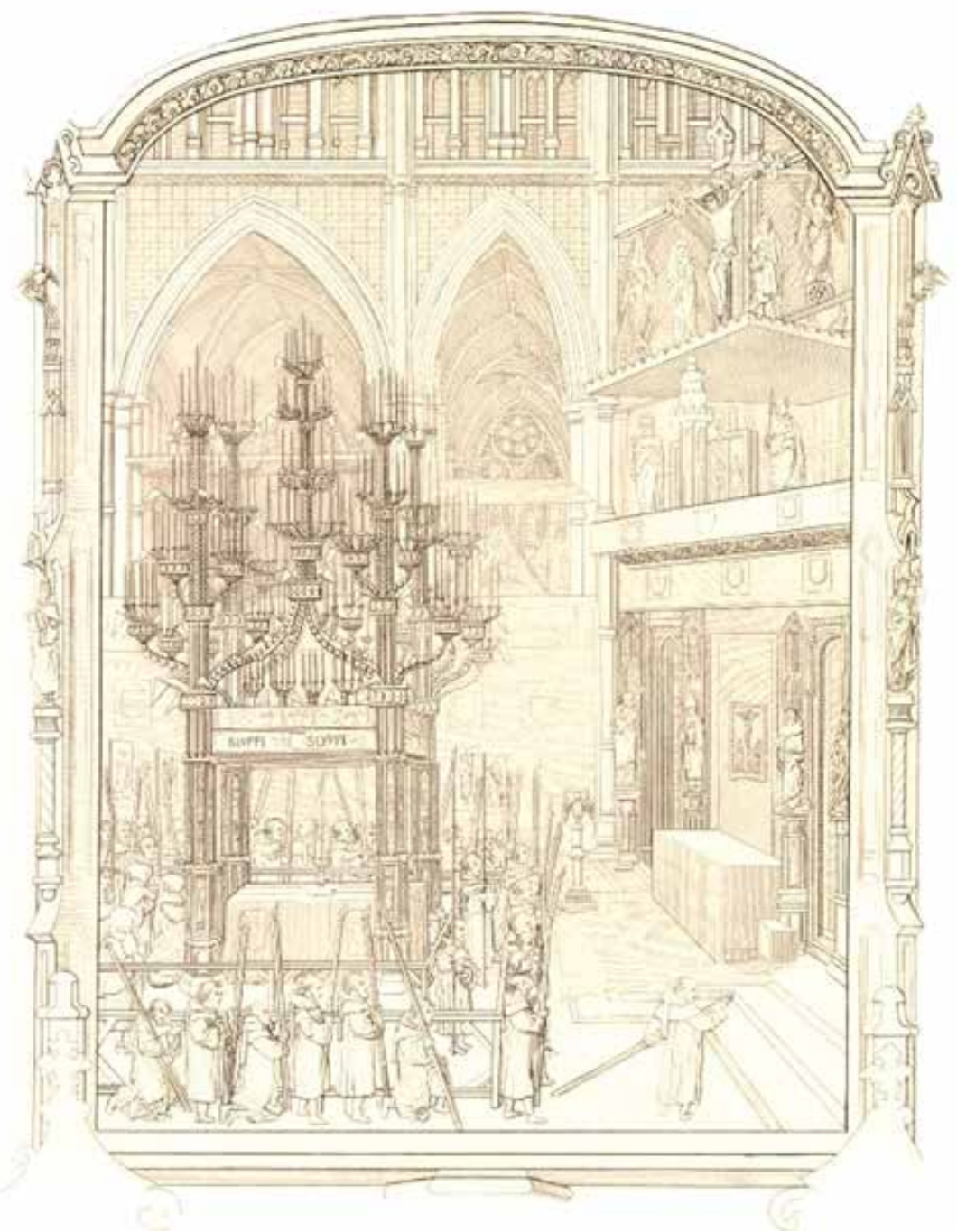

Fig. 9. Túmulo de John Islip erigido en Westminster en 1532,

según el Obituary Roll of John Islip, abbot of Westminster. Grabado realizado en 1808 para Vetusta Monumenta, vol. IV, pl. XviII, Londres, 1815 
En el diario de Machyn leemos esta descripción del túmulo erigido en memoria de la reina Juana:

The xvii day of Juin was the hersse fenyssyd at Powlles a-boyffe the qwyer with ix prensepalles garnyshyd, (the) goodlest that ever was sene, and all the prensepalles covered with blake velvett, and the mageste of taffata and the frynge [gold]. ${ }^{36}$

Se trataba de una construcción, situada entre el altar mayor y el coro, de forma octogonal, con un total de nueve pináculos, rodeado además de barreras dobles - «a sumptuous herse viii squared of ix pryncipalls [...] railed with double barriers»-. ${ }^{37}$ Estas barreras eran otro elemento muy repetido en la arquitectura efímera de los funerales ingleses: una barrera de madera que rodeaba el túmulo, separaba este del resto del templo, y generaba un espacio a su alrededor que era ocupado por los reyes de armas y los dolientes, especialmente el principal mourner, permitiendo así destacar a los protagonistas del acto y el desarrollo cómodamente de ciertos elementos del ceremonial, como el momento de la ofrenda. ${ }^{38}$ En ocasiones, como ocurrió con el túmulo dedicado a doña Juana, las barreras eran dobles, es decir el túmulo contaba con un doble perímetro. El conjunto se remataba con una estructura denominada en la documentación dome, como si de una forma cupulada o abovedada se tratase. En la parte inferior, representando a la difunta, se dispuso un ataúd. Machyn afirma que «the bare frame cost XV $£$. the carpynter dute»..$^{99}$

Tanto la ornamentación del túmulo como de la catedral londinense siguió el modelo del denominado "funeral heráldico», típicamente inglés, donde la decoración a base de escudos y banderas era fundamental, y se encontraba reglamentado hasta el más mínimo detalle, en lo que se refiere a número, forma y tamaño de las enseñas, en función de la posición social del finado.

El de doña Juana contó con numerosos escudos y banderas, destacando doce banderas que ornamentaban los laterales de la estructura. Estas mostraban una interesante heráldica. La primera partida con Castilla y León cuartelada, y las armas de Inglaterra; la segunda partida de Sicilia e Inglaterra; la tercera, con las armas de Castilla; la cuarta, con las de León; la quinta, mostraba las de Aragón; la sexta, las de Sicilia; la séptima partida, con las armas de Castilla y León; la octava partida, de Aragón y Sicilia; la novena, era cuartelada de Castilla y León; la décima, cuartelada de Aragón y Sicilia; la oncena era partida, mostrando en un lado las armas cuarteladas de Castilla y León, y en el otro, partido, las de Aragón y Sicilia; mientras que en la número doce, partida,

36. Nichols (ed.), The diary, p. 90

37. College of Arms, I.14, fol. 111.

38. WOODWARD, The theatre, pp. 30-35. El túmulo llega a considerarse superfluo si no hay ceremonia de ofrecimiento.

39. Nichols (ed.), The diary, p. 90. 


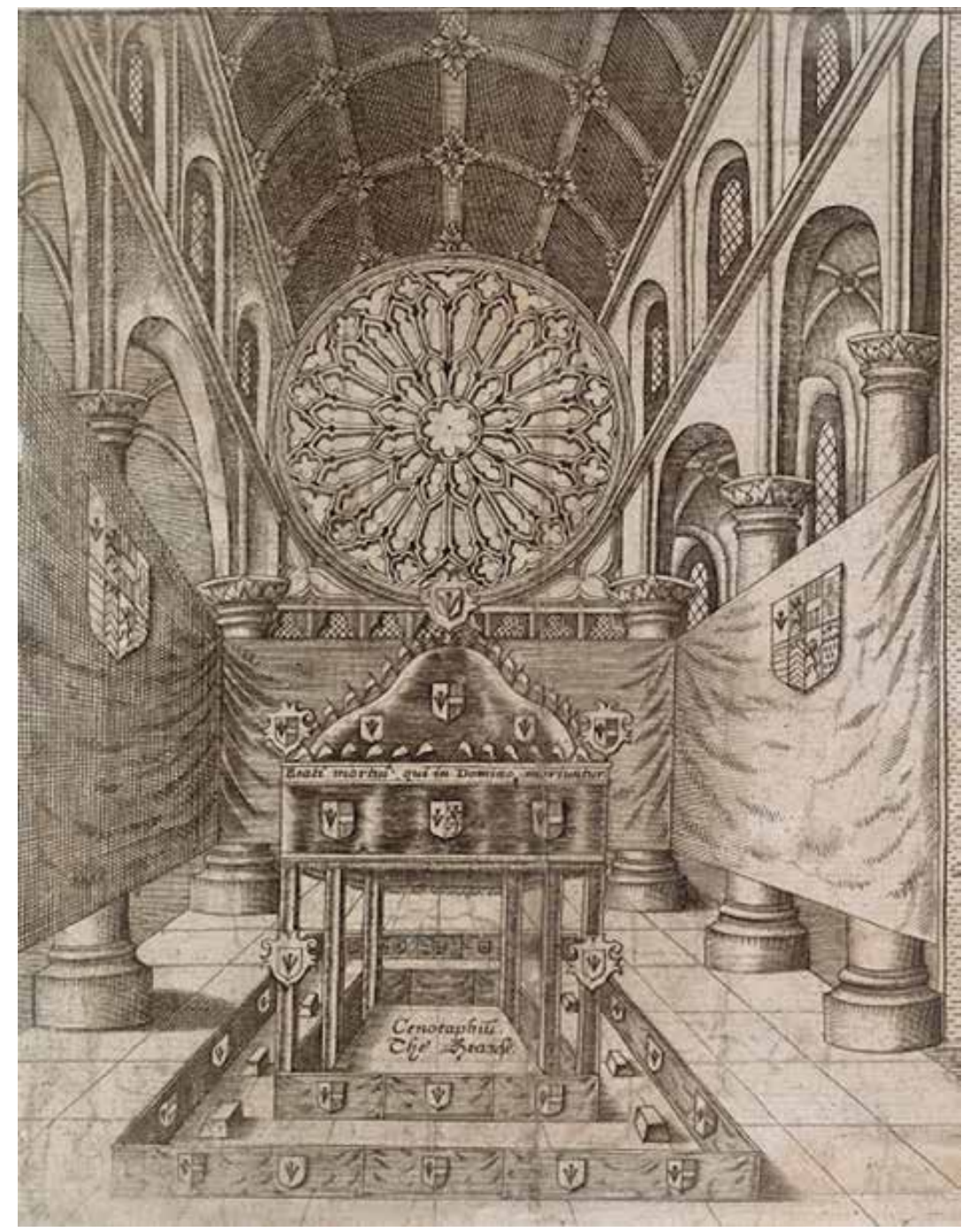

Fig. 10. Thomas Lant (dibujo) y Theodor de Bry (grabado), Procesión fúnebre de sir Philip Sidney, Londres, 1587. Detalle del túmulo

aparecían las armas de Borgoña y de España. ${ }^{40}$ Una bandera más, que se situó junto a la representación de la difunta, mostraba la heráldica de doña Juana -«of her armes alone»-. Llama la atención la presencia de la heráldica inglesa, que nada tenía que ver con doña Juana. 
Esta decoración se complementaba con:

iiii banners of Sayntes at iiii corners of the Trynity, our Lady, Saynt James, et Saynt John the vangelist [sic], holden by iiii heralds et pursuivants, Richmond, Yorke [sic], Lancaster, heraults, et by Rouge Croix pursuivant. ${ }^{41}$

La elección de las imágenes representadas no es casual. Así, Santiago y san Juan Evangelista son santos vinculados a España y sus monarcas. En los funerales ingleses era frecuente la aparición de estas banderas, especialmente Nuestra Señora y la Trinidad, junto con la representación de san Jorge, patrón de Inglaterra. ${ }^{42}$

Además de estas banderas de iconografía religiosa, había también una inscripción en letras doradas, que rezaba «Sper mea in Deo est, fringed with black silk gold». En el remate del túmulo, se colocaron las representaciones de los cuatro evangelistas. ${ }^{43}$

El resto de la iglesia se decoró con escudos de armas y telas negras, como era habitual. ${ }^{44}$ Señala Machyn cómo:

[...] all the qwyre and a-boyffe the qwyre and the sydes and ondur [foot] and the body of the chyrche one he ${ }^{a}$ hangyd with blake and armes, and with xxxxvi dosen of pensells of sylke welvett with gold and selver and xvi banes-rolles of armes and iiii banners of whyt emages wroght with fyne gold. ${ }^{45}$

La decoración estuvo a cargo, principalmente, de Nicholas Lyzarde y Thomas Childe. El primero, de origen francés y conocido también como Lizard, ocupó el cargo de serjeant painter entre 1554 y 1571, y participó en labores decorativas, propias de su oficio. ${ }^{46}$ El serjeant painter dirigía a todo el equipo de artistas que trabajaban para la casa real en aspectos fundamentalmente ornamentales y de carácter heráldico, tanto vinculados a episodios efímeros -como los funerales- como a la arquitectura palaciega. Thomas Childe fue un pintor citado siempre en relación con labores ornamentales, en ocasiones junto a otros miembros de su familia, fallecido en 1569. ${ }^{47}$ Además, como pintor decorativo, Lizard se encargó también de las ornamentaciones en los funerales de Eduardo VI, Carlos V, Enrique II de Francia, Juan III de Portugal y el emperador Fernando I, así como de las relativas a la coronación de Isabel I. ${ }^{48}$ En algunas de estas ocasiones colaboró con Thomas Childe. ${ }^{49}$ Lyzarde se

41. College of Arms, I.14, fol. $111 \mathrm{v}$.

42. LOACH, «The Function of Ceremonial», pp. 62-64.

43. College of Arms, I.14, fol. $111 \mathrm{v}$.

44. Cfr. Woodward, The theatre, pp. 28-30.

45. Nichols (ed.), The diary, p. 90.

46. ERna Auerbach: Tudor artists: a Study of Painters in the Royal Service and of Portraiture on Illuminated Documents from the Accession of Henry VIII to the Death of Elizabeth I, Londres, 1954, passim. 47. Idem.

48. Ibidem, pp. 78-80, p. 95, pp. 111 y 112 , pp. 145 y 146.

49. Al menos en las decoraciones de los funerales de Eduardo VI y Juan III. 
encargó de las banderas heráldicas y de las cuatro banderas de santos, así como de treinta y seis docenas de pequeñas banderolas principalmente, ${ }^{50}$ mientras que Childe se ocupó de los escusones, algunos en papel, y de los escudos que portaron en sus ropajes los pobres de la comitiva fúnebre. ${ }^{51}$ Además, pintó y doró la estructura del túmulo. ${ }^{52}$

El embajador veneciano Giovanni Michiel escribió a François Venier, dogo de Venecia, el día 17 de junio, indicando cómo la reina había pagado los lutos «et oltra le cere et apparato, ch'e stato bellissimo meno di 6 in 7 mila ducati».53 En la crónica de los franciscanos menores de Londres, se indica que las exequias se hicieron «with a goodly herse as ever was sene». ${ }^{54}$ Parece que todos los que lo vieron coincidieron en afirmar que el túmulo fue una obra digna de mención.

Además del túmulo y la decoración de la catedral, los gastos incluyeron los lutos para los dolientes, los embajadores del emperador, Portugal, Venecia y Francia, los oficiales de la casa real, los oficiales de armas, los regidores de Londres, así como de ciento veinte pobres. En total, los gastos ascendieron a más de $1000 £,{ }^{55}$ cantidad nada desdeñable. Finalizada la construcción del túmulo, en la noche del 17 y en la mañana del día 18, tuvieron lugar los actos religiosos: «Over nyght durge and the morrow masse». ${ }^{56}$ Giovanni Michiel narra cómo:

Siamo venuti qua hoggi dalla Corte sei di questi principali signori spagnuoli et l'ambasciador dell' Imperator ed io, essendo rimasto la quello di Portogallo, per essere indisposto, invitati tutti dal Consiglio Regio, per nome della Serenissima Regina, ad honorar le essequie della Regina di Spagna, le quali nella chiesia maggiore si San Paulo hoggi al vespero con gran solennita si sino comincie et domani doppo la messa finiranno, essendovisi in compagnia nostra trovato anche l'Ambassiator di Francia, invitato como noi, il quale cosi in chiesa como la sera, in casa del vescovo, alla cena che in compagnia delli Signori del Regno

50. College of Arms, I.14, fol. 114 v. Por las doce banderas heráldicas cobró doce libras, por la bandera con las armas de la reina sesenta chelines, por las cuatro banderas de santos ocho libras, y por las banderas pequeñas veintiuna libras y doce chelines. Realizó también otras pequeñas labores, cobrando por todo sesenta libras y veintitrés chelines. Cfr. The National Archives, E 101/427/14, s/f.

51. College of Arms, I.14, fol. 114 v. Cobró por todo ello veintiséis libras y dieciocho chelines. Cfr. The National Archives, E 101/427/14, s/f.

52. The National Archives, E 101/427/14, s/f: «John Childe for gilding and paynting of the maiestie with the dome». Por estas labores recibió ciento diecisiete libras, trece chelines y ocho peniques.

53. Friedmann (ed.), Les dépêches, p. 61.

54. John Gough Nichols (ed.): Chronicle of the Grey Friars of London, Londres, 1852, p. 96.

55. Exactamente los gastos ascendieron a $1068 £ 11 \mathrm{~s}$. The National Archives, E 101/427/14. Por ejemplo, Enrique VII gastó $566 £ 16 \mathrm{~s}$ en el funeral del príncipe Arturo. Cfr. STeven J. GunN y Linda MonckTon: Arthur Tudor prince of Wales. Life, death and commemoration, Woodbridge (Suffolk), 2009, p. 80. Más tarde, el gasto por las exequias por el rey de Francia Enrique II, celebrados en septiembre de 1559, ascendió a $789 £ 10 \mathrm{~s}$ 10d. Cfr. JOHN STRYPE: Annals of the Reformation and establishment of Religion and other various occurrences in the Church of England, during the first twelve years of Queen Elizabeth's happy Reign, Londres, 1709, p. 129; y JoSEPH STEVENSON (ed.): Calendar of State Papers, foreign series, of the Reign of Elizabeth, 1558-1559, I, Londres, 1863, p. 546. Las cantidades se anotan en libras ( $£$ ), chelines (s) y peniques (d). 240 peniques hacen una libra, y esta equivale también a 20 chelines.

56. Nichols (ed.), The diary, p. 90. 
ci fu preparata ha havuto il luogo suo. Non havera importato questa spesa, considerato il gran numero di persone che vi sono intervenute, tutte vestite con nobbe lunghe di duolo, donate a tutti per liberalita di Sua Maesta, et oltra le cere et apparato, ch'e stato bellissimo meno di 6 in 7 mila ducati. ${ }^{57}$

La noche del día 17 se celebró un oficio de difuntos en las vísperas, oficiado por el obispo de Londres -Edmund Bonner, quien ya había ocupado el cargo entre 1529 y 1549, y fue azote de los protestantes durante el reinado de María- y en el que participaron diversos nobles, «and mony mornars, the forst a stranger and the yerle of Shrusbere, and yerle of Penbroke, my lord treysorer, ser Recherd Sowthwell, and mony mo as Englys as Spaneards», ${ }^{58}$ y los embajadores del emperador, Francia y Venecia, pues el de Portugal se encontraba indispuesto, como relató Giovanni Michiel..$^{59}$

En la iglesia de San Pablo, donde «were placed in the body of the church vi ${ }^{\mathrm{xx}}$ poors men in black gowns et hoods on their heads and badge of the defunct armes in losange on their shoulders et torches light in their hands, divided on by the syde $L X »,{ }^{60}$ esperaba el obispo. La comitiva fúnebre entró en el templo, siendo flanqueada por los dichos pobres vestidos de luto, estando compuesta de la siguiente manera:

The proceeding.

Noble men et gentlemen in black gowns et hoods on their shoulders two on two.

Officers of armes wearing their cotes of armes their hood on their heads two on two.

ix mourners an Englishman et a Spaniarde.

The marquis of Winchester. The marquis de las Navas.

The marquis de Valea. The earl of Shrewsbury.

The earl of Pembroke. Le conte de Horne.

Le conte de [en blanco]. The lord Admirall.

Then garter in the quenes cote of armes before the chief mourner.

Le contye de Fery [sic] his trained borned and assisted by a gentleman huissher. Then following the ambassadors that is to sayd the ambassador of the emperor, the ambassador of the french kings, and the ambassador of Venice, proceeding all there togedere them pore in the middle of them, and so conducted to the herse by the officers of armes and there planed accordingly. ${ }^{61}$

57. FriedmanN (ed), Les dépêches, p. 61.

58. Nichols (ed.), The diary, p. 90.

59. En efecto se libraron ciertas cantidades de tela para sus lutos: The National Archives, E 101/427/14, s/f, «Livereys for the embassadours. The embassadoure for the emperor for his mourning robes viii yarde, iii pages iiii yardes, the embassadoure of France viii yardes, ii pages iii yardes, the embassadoure of Venice viii yardes, two pages iiii yardes, the embassadaure of Portugale viii yardes, ii pages iiii yardes. xlviii yarde». La yarda equivale a 0,9144 metros.

60. College of Arms, I.14, fol. 112. Mientras en el documento del College of Arms se lee perfectamente la cantidad de 120 pobres, Machyn en su diario apunta: «and a vii skore powre men havyng nuwe blake gownes, and evere man holdyng torchys». Nichols (ed.), The diary, p. 90.

61. College of Arms, I.14, fol. 112. 
El conde de Feria, Gómez Suárez de Figueroa, a la postre embajador del rey en Inglaterra, actuó como chief mourner, representando al soberano. ${ }^{62}$ Más tarde, en 1558, realizará el mismo papel en las honras fúnebres del emperador Carlos V..$^{63}$ Entre los nobles españoles que participaron como dolientes, vemos al marqués de las Navas, Pedro de Ávila y Zúñiga, mayordomo de Felipe II. También al conde de Horn, Philippe de Montmorency, capitán de los archeros de Corps, que a la postre caería en desgracia por ser afín al príncipe de Orange, siendo ejecutado en Bruselas en 1568. El «marqués de Valea», bien podría ser Martín Cortés Zúñiga, hijo de Hernán Cortés y marqués del Valle de Oaxaca, que acompañó al rey a Inglaterra y luchó junto a él en San Quintín. Por otro lado, ese conde que aparece sin denominación en el documento antes citado debe ser el cuarto conde de Fuensalida, Pedro López de Ayala, pues este recibió lutos. ${ }^{64}$ En las cuentas del funeral se indica que don Pedro de Córdoba, otro de los mayordomos del rey, recibió asimismo sus lutos. ${ }^{65}$ Otros nobles que acompañaron a Felipe a Inglaterra, sin que conste que participaran en las honras fueron, por ejemplo, el almirante de Castilla y el duque de Alba. ${ }^{66}$

La comitiva llegó al túmulo y ocupó sus lugares, sentándose en los puestos asignados a cada uno en el coro de la iglesia, donde se había dispuesto la construcción. Una vez todos estuvieron acomodados, el heraldo Chester comenzó a decir «in french in a loude voyce» lo siguiente:

De votre charite prieres pour lame du tres haulte et puissante princesse Joanne fien royne de Spaigne, d'Aragone, Cicille et du Navarre, et mere du tres hault et tres puissant prince l'empereur Charles le cinquiesme de ce nome et pour tous les trespasses, pater noster. ${ }^{67}$

Inmediatamente después comenzó el acto religioso, oficiado por el obispo de Londres «with vi assistants in pontificalibus». ${ }^{68}$ Terminada la ceremonia, la comitiva dejó la iglesia y se dirigió al palacio del obispo. ${ }^{69}$

La misa de funeral tuvo lugar al día siguiente. Los participantes se prepararon en la residencia de Bonner y desde allí se dirigieron a San Pablo, procediendo

62. The National Archives, E 101/427/14, s/f, «The county Feri comme chief mourner for his mourning robes viz hood, sloppe and mantell, xvi yardes, ii pages iiii yardes».

63. Stevenson (ed.), Calendar of State Papers, p. 38

64. The National Archives, E 101/427/14, s/f.

65. Ibidem.

66. Los pormenores del viaje a Inglaterra en ANDRÉs MuÑoz: Viaje de Felipe II a Inglaterra, Zaragoza, 1554, (reimpreso en ed. de Pascual de Gayangos, Madrid, 1877). Un listado de los nobles que acompañaron a Felipe en Louis Prosper Gachard (ed.): Collection des voyages des souverains des Pays-Bas, vol. 4, Bruselas, 1882, p. 422

67. College of Arms, I.14, fol. $112 \mathrm{v}$.

68. Ibidem.

69. Si bien el obispo de Londres poseía una residencia oficial en Fulham, además de otras casas, solía habitar un palacio junto a San Pablo, adosado al lado noroeste de la catedral, y desaparecido tras el incendio de 1666. Cfr. William Douglas Simpson: «The palaces or town houses of the bishops of London", Transactions of the London and Middlesex Archaeological Society, 1 (1905), pp. 13-71, que aporta numerosos documentos y planta del edificio. 
en la misma forma que el día anterior, «and so began the mass sang by the byshop of London and his assistants of the deanery». ${ }^{70}$ Tuvo también lugar la ceremonia del ofrecimiento, acto fundamental en los funerales ingleses, protagonizada por el chief mourner, el duque de Feria, que ofreció una pieza de oro, siendo asistido por un ujier y conducido por los oficiales de armas, regresando luego a su lugar. Tras él, los otros dolientes y los embajadores, hicieron lo mismo, y a continuación los regidores de Londres, y finalmente el resto de nobles asistentes. ${ }^{71}$ Tras el ofrecimiento, tuvo lugar el sermón.

En estos actos, el deán John Feckenham jugó un papel destacado. ${ }^{72}$ En un principio, parece que el predicador designado fue George Day, obispo de Chichester, ${ }^{73}$ quien ya había realizado el sermón en el funeral de Eduardo VI y durante la coronación de la reina María, pero finalmente no pudo hacerse cargo de dicha tarea. ${ }^{74}$ Feckenham era un monje benedictino que retomó el hábito con la vuelta del catolicismo a Inglaterra. Ocupó el puesto de deán de San Pablo, así como el de capellán de la reina y predicador, y desde noviembre de 1556 fue abad de la restaurada abadía de Westminster. Junto a otros quince monjes que volvieron a su orden, se convirtieron en los apóstoles del catolicismo en Inglaterra, adquiriendo un papel importante en la lucha contra los protestantes. ${ }^{75}$ Sus sermones eran cuidados discursos contra los enemigos de Roma. Algunos de ellos fueron impresos en vida de Feckenham, siendo uno A notable Sermon, que vio la luz en Londres en agosto de $1555,{ }^{76}$ texto que el predicador leyó durante el funeral de la reina Juana, y que giró en torno al tema de la preparación ante la muerte, partiendo del capítulo 32 del Deuteronomio ${ }^{77}$ y refiriéndose al tema de las «Cuatro últimas cosas»: la muerte, el juicio divino, los castigos del infierno y la gloria del Cielo, ${ }^{78}$ en conexión con la defensa del catolicismo. ${ }^{79}$ Feckenham habló

70. College of Arms, I.14, fol. 113

71. Idem.

72. También recibió lutos a costa de la casa real. The National Archives, E 101/427/14, s/f, «The dean of Paulus preacher, for his gowne, vi yardes».

73. George Day fue obispo de Chichester entre 1543 y 1551, si bien su oposición al protestantismo hizo que el joven monarca Eduardo VI le privase de su dignidad, retornando a ella entre 1553 y 1556, cuando murió.

74. Strype, Ecclesiastical, p. 220: «[...] Master Dean, to whom I wrote to make the sermon, who must assuredly do it, for my Lord of Chichester cannot attend it [...]».

75. Sobre el papel de Feckenham en la restauración del catolicismo, $c f r$. DufFy, Fires of Faith.

76. Aparece recogido en Elizabeth M. Nugent (ed.): The thought and culture of the English Renaissance. An anthologhy of Tudor prose 1481-1555, Cambridge, 1956, pp. 372-375.

77. Deuteronomio, 32-29, «Es gente sin consejo / No tienen conocimiento; / Si fueran sabios, comprenderían esto / Y atenderían a lo que les espera».

78. Un ejemplo de este tema cristiano, con alusión al citado capítulo del Deuteronomio puede verse en la conocida como Mesa de los Pecados Capitales, obra de El Bosco, adquirida por Felipe II y enviada a El Escorial en 1574.

79. El sermón, tanto en espacios abiertos -especialmente el púlpito de Paul's Cross- como en el templo, se convirtió en recurrente arma política y religiosa en la Inglaterra del siglo xvi. Sobre este tema, cfr. William Wizeman: The Theology and Spirituality of Mary Tudor's Church, Aldershot, 2006, pp. 28-31; TORRANCE Kirby: «The public sermon: Paul's Cross and the culture of persuasion in England, 1534-1570», Renaissance and Reformation / Renaissance et Réforme, 31.1 (2008), pp. 3-29; MARY MORRISEY: Politics and the Paul's Cross Sermons, 1558-1642, Oxford, 2011; Torrance Kirby y Paul G. Stanwood (eds.), Paul's Cross and the Culture of Persuasion in England, 1520-1640, Leiden, 2014. 
de la «late plague of errors and heresies», e instaba a los ingleses, comparados con la oveja perdida, a volver «again into the fold and unity of Christ's Church» $y$ «to defend the Catholic faith and religion of God», afirmando antes de finalizar que «if God be on our side, who can be against us?». ${ }^{80}$

Para finalizar, tras el sermón, el coro cantó Libera Me, y el obispo y sus asistentes abandonaron el altar recorriendo el cuerpo de la iglesia, seguidos por los dolientes y los embajadores, conducidos todos por los oficiales de armas, retornando al palacio episcopal, donde «there was prepared for them a sumptuous dyner, where they dyned with many other noblemen spanyarde all at one long table». ${ }^{81}$ Machyn - «after messe a grett dener at the bysshope of London('s) plasse, and gret plente»- ${ }^{82}$ y el embajador veneciano, ${ }^{83}$ recogen también este hecho, que se celebró siguiendo con la costumbre de ofrecer un banquete en recuerdo del finado. ${ }^{84}$

Al día siguiente, lord Treasurer -William Paulet, primer marqués de Winchester- encargado de los gastos de la casa real, acudió a San Pablo con los oficiales de armas, pues había «ordered that all things shuld remayne, herse, hangyngs and all things», hasta que el rey y la reina lo dispusieran. ${ }^{85}$ Así, el túmulo estuvo en pie varios días. La crónica de los franciscanos menores de Londres recoge cómo «stode a vi. or vii. days after». ${ }^{86}$ En efecto, el día 25 el tesorero acudió a San Pablo con los oficiales de armas para desmontar la decoración fúnebre, la cual, incluyendo la madera del túmulo, fue entregada a los dichos, como solía ser costumbre. ${ }^{87}$

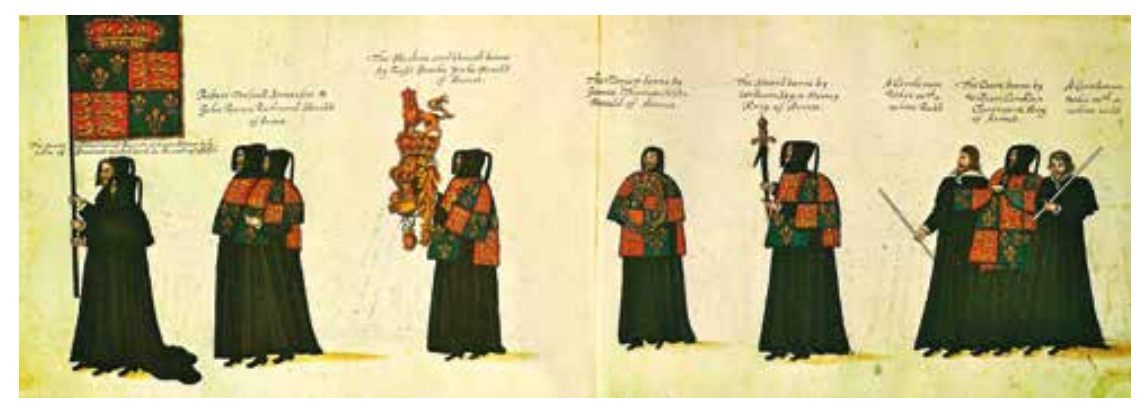

Fig. 11. Atrib. a William Camden, Procesión fúnebre de Isabel I de Inglaterra, 1603. Londres, British Library, MS Additional 35324. Detalle del cortejo, mostrando la participación de los heraldos del College of Arms

80. NugEnt (ed.), The thought and culture, pp. 372-375.

81. College of Arms, I.14, fol. $113 \mathrm{v}$.

82. Nichols (ed.), The diary, p. 90.

83. Friedmann (ed.), Les dépêches, p. 61.

84. WOODWARD, The theatre, pp. 35-36.

85. College of Arms, I.14, fol. $113 \mathrm{v}$

86. Nichols (ed.), Chronicle, p. 96.

87. College of Arms, I.14, fol. 114. Por ejemplo, en 1559, tras las exequias por el rey de Francia Enrique II, "the hearse was taken down by the heralds; who, as their fees, had all that was about it; both cloth, velvet, sarcenet, banners, escutcheons of arms, banner-staves, rails, etc.». Cfr. STRYPE, Annals, p. 192. 
El papel de los oficiales de armas era clave [Fig. 11]. Ellos velaban por el buen funcionamiento de los actos, se encargaban de guiar a los participantes por el entramado de gestos y acciones, y eran también actores activos participando en momentos puntuales. En los funerales por la reina Juana participaron varios, a cuya cabeza estaba el rey de armas de título Jarretera, sir Gilbert Dethick, que ostentaba el cargo desde $1550 .{ }^{88}$ Junto a él participaron el rey de armas Clarenceaux; los heraldos Chester, Richmond, York y Lancaster; y los persevantes Rouge Croix, Portcullis y Rouge Dragon. ${ }^{89}$ No solo recaía en ellos el hecho de la organización del funeral, sino también la supervisión de los motivos heráldicos, tan importantes en la decoración del túmulo y la iglesia. Además, los oficiales del College of Arms tenían el monopolio de la organización de los funerales heráldicos, y recibían diversos pagos por ello, ${ }^{90}$ incluyendo como hemos dicho lo relativo a la ornamentación de la iglesia, de los que se les solía hacer merced.

Ni la reina María ni su esposo acudieron a la ceremonia. La corte se encontraba en el palacio de Hampton Court, a donde se había trasladado en abril para mayor descanso de la reina y donde se tenía previsto que alumbrara al heredero. ${ }^{91}$ Además, la costumbre dictaba que las mujeres embarazadas se apartaran de la vida pública al menos cuarenta días antes y después del parto. María podría así, además, pasar los últimos momentos de su embarazo rodeada de las damas más importantes de su reino, que la atendían durante su retiro, alumbramiento y cuarentena..$^{92} \mathrm{El}$ embajador veneciano Michiel, en la misma carta que da noticia de la celebración de los funerales de la reina Juana, indica cómo «domani [día 18] ritornaremo in corte tutti pieni di speranza di trovar essa Serenissima Regina, o espedita del tutto felicemente, o in termine di doversi espedire molto presto», ${ }^{93}$ pues la reina tenía dolores que hacían prever un parto que nunca aconteció. Por su parte, el rey, «mentre si van preparando le essequie et il mortorio, stara

88. Walther H. Godfrey y Anthony Wagner: Survey of London Monograph 16: College of Arms, Queen Victoria Street, Londres, 1963, pp. 38-74.

89. College of Arms, I.14, fol. 114

90. The National Archives, E 101/427/14, s/f, «The rewards to the haurolde at armes for their fees at the tyme of the obsequie. $x \notin$. Item more in rewarde by the lorde Treasurer to Mr. Garter principall kinge at armes in recompense of the fringe of gold and silke restoures for to remain for the Kinge and Quenes majesties store in the great wardrobe. xiii $£$ vi s viii d. Somma: xxiii $£$ vi s viii d».

91. Cfr. Edwards, Mary I, pp. 267-268. También Harry Kelsey: Philip of Spain. King of England, Londres, 2012, p. 109. Simon Renard, embajador imperial, dice el día 4 de ese mes que los reyes dejan Londres para ir a Hampton Court, donde pasarían la Pascua, y más tarde -el día 14- afirma no saber cuánto tiempo estarían allí ni cuando regresarían a Londres. Cfr. ROyAll Tyler (ed.): Calendar of Letters, Despatches, and State Papers, Relating to the Negotiations Between England and Spain, XIII, Londres, 1954, pp. 153 y 161. Vandenesse, sin embargo, da en su diario la fecha de cuatro de mayo para el traslado a Hampton Court, $c f r$. Jean de VAndenese: «Journal des voyages de Philippe II», en Louis Prosper Gachard (ed.): Collection des voyages des souverains des Pays-Bas, vol. 4, Bruselas, 1882, pp. 20-21. Puede tratarse de un error, pues el cronista indica lo mismo el día cuatro de abril (ibidem, p. 19).

92. KeLSEY, Philip of Spain, p. 109. Así lo indica el embajador imperial Simon Renard en carta a su señor, en carta de 21 de abril. Cfr. Tyler, Calendar of Letters, p. 166

93. Friedmann (ed.), Les dépêches, p. 61. 
la Maesta Sua retirata, ne uscira in pubblico fin dopo l'haver satisfatto a questa cerimonia»..$^{94}$

Los funerales celebrados en Londres por la reina Juana supusieron, como otros actos del momento, una oportunidad para, por un lado, aglutinar a la nobleza inglesa en torno a los reyes, y fomentar la convivencia con los españoles; por otro lado, escenificar públicamente la vuelta al catolicismo, sin dejar pasar la ocasión de arremeter contra los protestantes; y también recordar la unión con los Habsburgo y que el monarca estaba más cerca de serlo de los territorios hispanos, una vez que doña Juana había desaparecido. La comitiva fúnebre, el oficio de Bonner y el sermón de Feckenham, y del mismo modo la ornamentación del túmulo, así lo certifican.

94. Ibidem. Por otro lado, en la tradición inglesa, el nuevo monarca no acudía al funeral de su predecesor. Cfr. LOACH, «The Function of Ceremonial», p. 61. 